\title{
Exercícios de sonhar junto: criatividade e experiências estéticas no acompanhamento de uma criança
}

\section{Dreaming together: creativity and aesthetic experiences on the accompaniment of a child}

\author{
Renata Monteiro Buelau ${ }^{1}$, Erika Alvarez Inforsato ${ }^{2}$, \\ Elizabeth M. F. Araújo Lima ${ }^{3}$
}

BUELAU, R. M.; INFORSATO, E. A.; LIMA, E. M. F. A. Exercícios de sonhar junto: criatividade e experiências estéticas no acompanhamento de uma criança. Rev. Ter. Ocup. Univ. São Paulo, v. 20, n. 3, p. 164-170, set./dez. 2009.

RESUMO: Este artigo apresenta o estudo de caso sobre o acompanhamento terapêtico de uma criança em vulnerabilidade social, atendida no Programa Permanente de Composições Artísticas e Terapia Ocupacional (PACTO), do Curso de Terapia Ocupacional da USP, entre os anos de 2004 a 2007. O estudo visou contribuir para a construção de conhecimento no campo de interface entre arte e saúde, dando destaque à importância da criatividade e das experiências estéticas nos processos de Terapia Ocupacional. Buscou-se, assim, verificar em que medida a abertura para o viver criativo potencializa a vida e possibilita a apresentação do mundo de um modo convidativo e não ameaçador. $\mathrm{O}$ acompanhamento mostrou-se extremamente rico para o processo da criança. A partir do trânsito pela cidade, do contato com outras pessoas, com elementos da cultura e da criação de um espaço de jogo na relação com a terapeuta, foi possível enfrentar as intermitências da vida de forma criativa e saudável.

DESCRITORES: Terapia Ocupacional. Criatividade. Atividades Humanas. Desenvolvimento Infantil. Estudos de caso.

\footnotetext{
1 Terapeuta Ocupacional do CAPS Adultos II Cidade Ademar da Organização Social Associação Congregação de Santa Catarina.

2 Terapeuta Ocupacional do Curso de Terapia Ocupacional do Departamento de Fisioterapia, Fonoaudiologia e Terapia Ocupacional da FMUSP.

3 Docente do Curso de Terapia Ocupacional do Departamento de Fisioterapia, Fonoaudiologia e Terapia Ocupacional da FMUSP. Endereço para correspondência: Rua Cipotânea, 51. CEP: 05508-900 - São Paulo, SP. E-mail: renatabuelau@yahoo.com.br / beth. lima@usp.br
} 
"Tudo o que não invento é falso".

(Manoel de Barros)

\section{INTRODUÇÃO}

$\mathrm{A}^{\mathrm{p}}$ pesquisa ${ }^{1}$ que aqui apresentamos foi construída como um estudo de caso realizado sobre o Acompanhamento Terapêutico (AT) de uma criança em situação de vulnerabilidade social, articulado às ações de Terapia Ocupacional (TO) e ao trabalho com atividades. $\mathrm{O}$ estudo foi construído a partir do envolvimento ativo dos pesquisadores na coleta, análise e interpretação dos dados, através de um planejamento flexível para a observação da realidade estudada em seu devir, possibilitando uma visão mais abrangente e aprofundada desta realidade. Para Gil (1991),

(...) a análise de uma unidade de determinado universo possibilita a compreensão da generalidade do mesmo ou, pelo menos, o estabelecimento de bases para uma investigação posterior, mais sistemática e precisa (p. 79).

A abordagem qualitativa no campo da Terapia Ocupacional rompe com padrões de investigação que seguem parâmetros definidos previamente pelo pesquisador, e permite lidar com fenômenos complexos (VILLARES, 1998).

No desenvolvimento do projeto, foi realizado estudo bibliográfico sobre temas relevantes para a pesquisa. Além disso, foram planejadas as atividades desenvolvidas nos atendimentos, e realizadas discussões em reuniões clínicas da equipe do Programa Permanente de Composições Artísticas e Terapia Ocupacional (PACTO). A participação nos diversos espaços que envolveram a pesquisa foi registrada de acordo com a metodologia de observação participante (GIL, 1999) por meio de anotações em caderno específico (BUELAU, 2006). O acesso a documentos e dados de prontuário, incluindo a história de vida, também foi utilizado tanto para a organização da proposta quanto para a avaliação dos resultados.

A análise do material coletado foi realizada a partir da articulação dos dados obtidos nos registros com a história de vida, com a literatura pesquisada e com as discussões com a equipe.

Entendendo a criatividade e as experiências estéticas como elementos fundamentais para a existência saudável, este estudo visou contribuir para a construção de conhecimento no campo da interface entre as artes e a saúde, dando destaque à importância da criatividade nos processos de TO. Buscou-se, assim, verificar em que medida a abertura para o viver criativo potencializa a vida e possibilita a apresentação do mundo de um modo convidativo e não ameaçador.

O compromisso ético da clínica aqui desenvolvida refere-se à valorização da vida em sua capacidade de criação, afirmando a subjetividade como um processo de constante auto-produção, engendrando os mais variados territórios existenciais, indissociáveis do campo cultural (ROLNIK, 1996). A saúde, nesse sentido, é pensada como um processo, abrangendo um contínuo movimento da pessoa em direção ao bem estar físico, psíquico, social e cultural. Ser saudável não é estar livre de doenças, é poder lutar ativamente contra os sofrimentos utilizando recursos individuais e ambientais; é perseguir desejos, criar alternativas. Saúde é liberdade de ação (DEJOURS, 1986).

\section{Encontro, experiência estética e constituição do self}

A criança, aqui chamada de Gustavo, morava com o pai, a mãe e dois irmãos em uma pequena casa na favela do Jaguaré, em São Paulo. Foi encaminhado ao PACTO aos 4 anos de idade pela creche que freqüentava na ocasião, com referências a traços de agressividade no contato com outras crianças e questões de violência familiar. Gustavo participou de atendimentos grupais por dois anos e meio, até que o processo do grupo foi encerrado, em junho de 2006. $\mathrm{O}$ acompanhamento terapêutico foi realizado entre agosto de 2005 e junho de 2007.

Quando chegou ao PACTO, Gustavo tinha um olhar expressivo que parecia tentar transmitir um sentimento escondido que se aproximava do medo e da angústia. $\mathrm{O}$ olhar e os gestos velozes eram as características que mais chamaram atenção. Sua imprevisibilidade e agitação provocavam estranhamento, medo e distanciamento, trazendo dificuldade para o estabelecimento de contato com ele.

No início de sua participação no grupo de crianças, dificilmente entrava nas atividades grupais propostas pela equipe. Permanecia a maior parte do tempo sozinho

\footnotetext{
${ }^{1}$ A pesquisa “Criatividade e Experiências Estéticas em um Acompanhamento de Terapia Ocupacional: Um Estudo de Caso" foi desenvolvida como trabalho de conclusão de graduação Os atendimentos integraram as ações do PACTO. O projeto de pesquisa foi submetido e aprovado pela Comissão de Ética para Análise de Projetos de Pesquisa do Hospital das Clínicas da Faculdade de Medicina da Universidade de São Paulo (CAPPesq) em 23/03/2006, protocolo de pesquisa 1269/05.
} 
BUELAU, R. M. et al. Exercícios de sonhar junto. Rev. Ter. Ocup. Univ. São Paulo, v. 20, n. 3, p. 164-170, set./dez. 2009.

e nem sempre aceitava a aproximação das terapeutas. Chamava atenção a maneira frenética, e até um pouco desesperada, como trabalhava. Costumava colocar muita tinta no papel, misturando-as vorazmente até atingir uma tonalidade marrom-arroxeada. Corria por toda a sala, subia em uma pilha de colchões que lá havia e às vezes interferia rapidamente nas atividades das outras crianças. Em alguns momentos, quando aparentava estar muito envolvido com alguma atividade, começava a chorar inconsoladamente, sem que se pudesse identificar o motivo. Quando participava de jogos simbólicos e brincadeiras de faz-de-conta, trazia imagens violentas e muito parecidas com cenas do seu cotidiano.

A velocidade de seus movimentos só era interrompida quando Gustavo explodia em atitudes de intenso desespero, raiva e agressividade. Estagiárias e terapeuta tentavam aproximar-se dele de diversas formas, mas nada era suficiente para cessar sua agitação e instaurar um espaço de maior aproximação. Nos cadernos de registro dos atendimentos são encontrados relatos de situações que esboçam este contato. É o caso do trecho a seguir, que apresenta um importante acontecimento no processo de acompanhamento deste menino:

Enquanto todas as crianças brincavam juntas com um enorme pedaço de tecido, Gustavo permanecia no canto da sala batendo freneticamente em um pandeiro. Tentamos conversar com ele e sugerir que fosse brincar com as outras crianças, mas ele não esboçava qualquer tipo de reação. Nem um olhar, nem um movimento, nem uma palavra. Lá só havia um ritmo quase que insuportável aos ouvidos, que a cada nova tentativa frustrada de contato parecia aumentar. Quase vencida, olhei em volta e vi outro pandeiro. Peguei-o, sentei-me ao seu lado e, sem nada dizer, passei a imitar suas batidas no instrumento. Em um primeiro momento, ele apenas aumentou a velocidade e intensidade do ritmo. Eu o acompanhei. Ficamos por alguns segundos embevecidos naqueles movimentos exaustivamente repetitivos e incômodos. Quando já não era mais possível suportar aquele ritmo, Gustavo parou. Retomou então as batidas, mas, desta vez, ele criava algum tipo de ritmo e logo parava, esperando que eu o imitasse. Ficamos assim alguns minutos. Ele criando e eu reconhecendo sua criação. De repente, ele parou, colocou o pandeiro de lado e foi brincar com as outras crianças (BUELAU, 2004, p. 6).

Este acontecimento possibilitou uma aproximação de outra qualidade entre Gustavo e a estagiária do PACTO, e possibilitou a ele outra forma de estar no grupo. Ao bater desesperadamente no pandeiro, produzindo um som quase insuportável, Gustavo estava reproduzindo algo de sua corporeidade, buscando integrar elementos de sua experiência no mundo que o habitavam de forma desarticulada. A atitude da estagiária, de entrar neste ritmo reconhecendo-o como expressão de Gustavo pode ser considerada como um gesto poético, no sentido que lhe dá Safra (2005), pois articula em um único fenômeno a capacidade criativa dos sujeitos envolvidos, dando origem à comunicação humana e concedendo àquela situação a qualidade de fenômeno estético. Ou seja, foi a partir de uma presença atenta e acolhedora que o ato de bater no pandeiro pode ser vivenciado como uma experiência de criação. É importante ressaltar que criatividade, aqui, não é entendida como talento ou habilidade artística. Refere-se ao estar vivo, à ruptura e negação dos padrões, da repetição e dos ideais de outrem impostos a nós, em favor de realizar um eu no mundo (MAY, 1971).

O entendimento do processo de Gustavo apóia-se principalmente em estudos de Winnicott (1996), que afirmam que para se desenvolver de forma saudável, toda criança necessita, sobretudo no início da vida, de uma provisão ambiental satisfatória. Esta possibilita que a criança vá aos poucos constituindo seu self, o seu senso de continuidade, unidade, integração e existência no mundo, na presença de alguém que a auxilie nesse processo e a reconheça em sua singularidade. A mãe ou sua substituta, adaptando-se ativamente à criança, coloca-se ali onde esta, com sua ação, cria o mundo. Nessas condições, a potencialidade de alucinar permite ao bebê a experiência de que a mãe e o mundo são criações suas, e é nesta potencialidade que reside a base da capacidade criativa.

Mas, esse ambiente satisfatório é também um ambiente que possui falhas, que dão espaço à desilusão: o bebê vai aos poucos percebendo que ele não cria o mundo, mas um mundo, na presença de um outro. Este processo possibilita, gradativamente, o estabelecimento do que se denomina espaço potencial: um vazio que surge na ausência do outro que, podendo ser suportada, instaura uma área intermediária de experimentação, que poderá ser habitada pela criatividade (SAFRA, 2005).

Essa área intermediária de experiência, incontestada quanto a pertencer à realidade interna ou externa constitui a parte maior da experiência do bebê e, através da vida, é conservada na experimentação intensa que diz respeito às artes, à religião, ao viver imaginativo e ao trabalho científico criador (WINNICOTT, 1975, p. 30).

Nesta área intermediária ocorrem experiências estéticas, que por seu caráter sensível, material e criativo, são essenciais para a constituição e apresentação do self. São experiências através das quais um sujeito cria uma forma sensorial que dá conta de uma vivência. A experiência estética, no entanto, só é possível na presença de um outro 
que, ao validar o gesto de alguém como expressão de seu self, coloca a vida em movimento, instaurando um processo de vir a ser no mundo, no encontro com outros corpos.

O self, na definição de Safra (2005, p.27), "se constitui, se organiza e se apresenta por fenômenos estéticos"; sua constituição envolve elementos extremamente complexos, que vão além da linguagem discursiva.

(...) uma criança vai significando suas experiências tanto pelo uso da linguagem discursiva, que ela desenvolverá na relação com sua mãe, como também pela articulação de formas estéticas e simbólicas no campo sensorial de suas vivências (SAFRA, 2005, p.25).

Nesse sentido, a Terapia Ocupacional muito tem a contribuir. Ao criarmos um campo de experimentação onde formas estéticas e simbólicas podem ser inventadas e articuladas através da atividade humana e da abertura ao contato com a alteridade, promovemos um cuidado com a experiência dos sujeitos no mundo, fundamental para a criação de novos territórios existenciais e, conseqüentemente, para a produção de vida.

\section{Agressividade, movimento espontâneo e o viver criativo}

Após quase dois anos de participação no grupo, a equipe do PACTO avaliou que Gustavo necessitava de atenção mais individualizada, que se concretizaria através de um Acompanhamento Terapêutico (AT). A função desta intervenção foi sendo gestada para construir um espaço no qual o acompanhante ocuparia lugar de um corpo atento, vivo e presente; um corpo simbolizado e simbolizante que estaria com Gustavo ao longo dos acontecimentos.

Além disso, a intervenção no território, que caracteriza o AT, fortalece recursos, amplia redes e facilita o acesso a lugares públicos. Segundo Castro (2007), um "setting flexível", que se transforma constantemente, possibilita uma intervenção nas diversas áreas nas quais se desenvolve a ação do homem, como é proposto pela Terapia Ocupacional. $\mathrm{O}$ deslocamento por diferentes espaços amplia as possibilidades de relação, ação e criação, transformando a cidade em um verdadeiro espaço potencial.

O AT teve início no segundo semestre de 2005. Gustavo passou a ser atendido semanalmente em diversos espaços: sua casa, parques públicos, livrarias e também na sala de Terapia Ocupacional. Os primeiros meses de atendimento caracterizaram-se por uma aproximação entre acompanhante e criança. Aos poucos, foi-se percebendo que na maioria dos espaços freqüentados por Gustavo - inclusive sua casa -, ele era visto como terrível e agressivo, sendo sempre culpabilizado pelo que ocorria. Diante disto, veio a pergunta que se tornou eixo principal no atendimento de Gustavo: o que um ambiente como o seu provocava em sua vida e como fortalecê-lo e auxiliá-lo a desenvolver-se de uma maneira mais saudável, que lhe permitisse responder a este ambiente e se apropriar da realidade com um gesto singular?

Como vimos, o oferecimento à criança de um ambiente confiável é condição para a experiência da criatividade. Esta, por sua vez é fundamental para um desenvolvimento saudável. É somente a partir da capacidade criadora que conseguimos nos apropriar da realidade, inventar um mundo e nos relacionar com o outro. Segundo Winnicott (1996) é através da criatividade que sentimos a vida como digna de ser vivida. $\mathrm{O}$ aspecto fundamental da criatividade humana é a possibilidade de agir. A ação que é reconhecida por um outro significativo se humaniza e se transforma em gesto.

Segundo Winnicott (1994), já no início da vida o bebê apresenta motilidade e vitalidade dirigidas ao ambiente, que constituem as raízes da agressividade humana. Nesta perspectiva, a agressividade é um apetite pela vida, através da qual o bebê se satisfaz. A satisfação ocorre quando a movimentação do bebê em direção ao ambiente proporciona seu auto-reconhecimento e a transformação do ambiente estranho em um "campo-de-vida familiar" (COSTA, 2004).

Ao nascer, o bebê é mergulhado num campo de experiência. Através da movimentação ele encontra o mundo e vai constituindo seu self e diferenciando-se do ambiente. Caso haja um ambiente suficientemente bom, o bebê será capaz de desenvolver a sua agressividade em relação ao mundo; o movimento aleatório evolui para ações que exprimem amor e ódio, elementos que envolvem agressividade e que são fundamentais em toda relação humana.

Dando-se tempo para os processos de maturação, a criança se tornará capaz de ser destrutiva e de odiar, agredir e gritar, em vez de aniquilar magicamente o mundo. Dessa maneira a agressão concreta é uma realização positiva. (WINNICOTT, 1994, p. 102)

Ao longo do desenvolvimento, com a presença corporal da mãe, a criança consegue conciliar o amor e a agressão, tornando-se capaz de conquistar sua satisfação sem colocar em perigo o objeto de amor. Para Safra (2005) está em jogo aqui

(...) uma espécie de dança, com qualidades estéticas, que coloca o corpo da criança no mundo humano, transformando-o não só num instrumento de fazer, mas também num meio de expressão de vivências subjetivas (p.107).

Assim, agressividade é componente importante do 
desenvolvimento normal e está presente no movimento da criança em direção ao mundo. Todavia, um ambiente brusco e imprevisível pode gerar na criança uma ansiedade insuportável por não possibilitar a ela a elaboração de sua agressividade. Isto pode trazer à criança inseguranças das quais, muitas vezes, surge a violência ou uma tendência anti-social.

Nestas situações, explosões de agressão tornam-se freqüentes,

(...) a criança perde sua própria impulsividade e espontaneidade. O nível de ansiedade é tão alto que o ato de experimentar, que poderia fazê-la chegar a um acordo com a própria agressividade, torna-se impossível (WINNICOTT, 1996, p.74).

Essa agressividade, entretanto, pode ser afirmativamente lida como um ponto de força da criança na busca por encontrar alguém que ofereça resistência a este movimento e a ajude a inventar momentos nos quais ela seja capaz de encontrar objetos criativamente e sentir-se segura quanto aos seus sentimentos agressivos em relação ao mundo.

Essa perspectiva mais afirmativa da agressividade, porém, não prevalecia no entorno social de Gustavo, que tendia a julgar essas atitudes moralmente, com punições e recriminações. Além disso, havia comumente a exigência de que a criança explicasse sua atitude, o que nem sempre era possível, pois em geral ela não sabia o que estava acontecendo. A maior parte das cenas de agressividade de Gustavo surgiam de forma inesperada e incompreensível. Era como se uma avalanche de angústia, medo e raiva subitamente tomasse conta do seu corpo. Depois da agressão, Gustavo freqüentemente desatava a chorar, sem conseguir elaborar a situação.

\section{Destrutividade, envolvimento e atividade construtiva}

No início do AT, Gustavo demonstrava vontade de destruir aquilo que era feito juntamente com a acompanhante. Além disso, também dirigia gestos agressivos a ela e a outras crianças. O manejo, nesses momentos, era de simultaneamente oferecer resistência e acolher estes gestos impulsivos, redirecionando-os a uma ação construtiva.

Quando as vivências que se fazem na área intermediária da experimentação estão dificultadas, torna-se imprescindível o estabelecimento de uma relação na qual seja possível para a criança experimentar-se num ambiente que possa acolher seus gestos - criativos e às vezes agressivos -, possibilitando que criação e destruição possam integrar-se em atividades que potencializem a vida (SAFRA, 2005).
No início da vida, o bebê é capaz de aniquilar o mundo magicamente sem viver a ambivalência entre amor e ódio em relação a algum objeto. Com o desenvolvimento, ele torna-se capaz de amar e odiar um mesmo objeto; a ansiedade que surge em decorrência desta ambivalência pode ser suportada, transformando-se no sentimento de culpa. Se a criança pode reparar a situação através de uma contribuição ao ambiente, o sentimento de culpa é, então, aliviado. Quando a criança já consegue confiar no ambiente e na possibilidade de aliviar o seu sentimento de culpa sem inibir seus instintos agressivos, ocorre uma modificação deste sentimento. Surge a possibilidade dela se preocupar.

A criança está agora se tornando capaz de se envolver, de assumir a responsabilidade por seus próprios impulsos instintuais e pelas funções ligadas a eles. Isso fornece um dos elementos construtivos fundamentais do brincar e do trabalho (WINNICOTT, 1994, p.109).

É nesse aspecto que a abertura para o viver criativo também se faz importante, no sentido de fornecer a possibilidade para uma relação construtiva com a sociedade sem que seja necessário se submeter à realidade ou ter o seu gesto singular anulado. Para Winnicott (1994, p.96), "a agressão que não é negada, e pela qual pode ser aceita a responsabilidade pessoal, é aproveitável para dar força ao trabalho de reparação e restituição". Para o autor, por trás do jogo, trabalho e arte está o remorso inconsciente e um desejo de começar a corrigir as coisas.

Assim, nos atendimentos, foram sendo inventados espaços nos quais Gustavo poderia confiar e se sentir seguro para apresentar-se com suas angústias, dificuldades e sentimentos, inclusive os agressivos. Dessa maneira, através de brincadeiras, passeios e atividades artísticas e de uma presença disponível, ele pode vivenciar a sua destrutividade sem resumir sua existência a ela. A sustentação das situações que aconteciam nos atendimentos foi instaurando para Gustavo um tempo de espera e um projeto de futuro. Cada vez mais, ele foi conseguindo tolerar as frustrações, o que abriu espaço para ele se sentir vivo e capaz. Nos registros dos últimos meses de atendimento encontramos com freqüência referências ao fato de Gustavo lembrar-se da pipa que havia destruído em atendimento e ao desejo de confeccionar uma nova. Isto levou a estagiária propor novamente a confecção de uma pipa.

Quando fomos tentar empiná-la, ela não voou. Diferentemente da primeira vez, quando cheio de raiva tentou amassar a pipa, Gustavo, levou-a para dentro da sala e disse que iria arrumá-la. Depois saímos para uma nova tentativa, desta vez muito bem sucedida. Gustavo vibrou. Corria, puxava a linha e repetia com euforia: "Eu consegui, eu consegui! A pipa foi lá longe no céu e eu que fiz sozinho!" (BUELAU, 2006, p.16). 


\section{Contornos, corpo e continência}

As questões trazidas por Gustavo aos atendimentos estavam fortemente ligadas à sua imagem corporal e à importância, para ele, da constituição de um contorno. Após alguns meses de acompanhamento, começou a explorar seu corpo, observando e imitando a maneira de se vestir dos garotos mais velhos. Olhava-se com freqüência no espelho, analisava seus movimentos e gostava de mostrar o que sabia fazer com seu corpo, muitas vezes com um caráter de competição ou desafio. Até mesmo nas atividades plásticas, este tema passou a aparecer. Em um dos encontros disse que queria desenhar seu corpo e a estagiária foi acompanhando e dando sustentação para a execução desse projeto.

(...) ele queria desenhar a cabeça e em seguida as pernas e as mãos. Sugeri que ele se tocasse e olhasse para o seu corpo para ajudá-lo no desenho. Aos poucos foi desenhando pescoço, braços, peito, joelhos e pés. Após terminar o contorno do desenho, ele o observou e, em seguida, colocou os pés mais para baixo, e aumentou a largura dos braços, fazendo-se mais alto e mais forte, como ele mesmo nomeou (BUELAU, 2006, p.24).

A questão da constituição de um contorno (LIMA, 1999), tanto em relação às atividades quanto ao espaço do AT, parecia fazer muito sentido para Gustavo. Nos momentos em que estava desenhando, Gustavo passou a demonstrar a necessidade de um contorno para que pudesse produzir. Antes de usar o pincel, sempre pedia um lápis para contornar. Somente após fazê-lo, utilizava o pincel para pintar dentro. Certa vez, se interessou muito por um pedaço de papelão no qual havia um corpo vazado. Colocou o papelão sobre uma folha e, com um lápis, contornou a figura, que apareceu no outro papel. Assim, os atendimentos passaram a ser organizados de maneira que houvesse sempre um espaço para trabalhar com o corpo.

A constância fornecida pela presença da estagiária, toda semana, significando, testemunhando e reconhecendo as singularidades e necessidades de Gustavo, e a manutenção e respeito ao seu ritmo, lhe proporcionou um ambiente seguro e, conseqüentemente, maior confiança no mundo. Winnicott denominou este fenômeno, que fornece à pessoa a experiência de continuidade, de holding. Em um ambiente que forneceu esta sustentação, tornou-se possível também a continência, ou seja, através da imaginação e da criação Gustavo foi aos poucos transformando suas experiências, dando a elas novos sentidos e camadas de simbolização. Estes contornos abriram para Gustavo a possibilidade para o surgimento do gesto espontâneo e da utilização da criatividade como uma forma de ressignificar suas experiências e se colocar no mundo. A confiança neste espaço possibilitou também a diminuição daquele ritmo excessivamente veloz de sua corporeidade.

\section{A experiência de sonhar junto}

No último ano de acompanhamento, Gustavo passou a dormir no percurso de ida e volta dos atendimentos, o que fomos entendendo como o estabelecimento de uma transição que colocava o AT no espaço do sonho. O acompanhamento forneceu-lhe um acolhimento que lhe possibilitou experimentar outros ritmos em seus movimentos, num espaço em que podia confiar.

Os acontecimentos que inicialmente nele rebatiam, agora penetravam em seu corpo. Gustavo já não experimentava o mundo como uma realidade incompreensível demais para ser suportada. O jogo, inicialmente estabelecido com a acompanhante, passou gradativamente a ser um convite de relação com o mundo. A partir do transitar pela cidade, do contato com outras pessoas, com elementos da cultura, ele começou a enfrentar as intermitências da vida de forma mais criativa e saudável.

Sua corporeidade, antes marcada por uma velocidade que o desorganizava, tornou-se aos poucos mais integrada, e através de seu olhar começamos a ver o desabrochar de uma curiosidade que se voltava para o mundo e para a vida.

Através das atividades realizadas no atendimento e do vínculo estabelecido, Gustavo pode conhecer diferentes formas de se relacionar com o entorno, com o outro e consigo mesmo, com movimentos no sentido de transpor estigmas e formas de relação até então estanques em sua vida.

Sua pipa pode, agora, voar alto pelo céu. O encontro com diversos fluxos, a produção de vivências do criativo e estados de arte engendraram uma processualidade em sua vida. A arte, o gesto, a metáfora e o brincar se configuraram como formas de criar o inédito, de instaurar a possibilidade de inserir as marcas de sua singularidade na realidade e criar novas marcas em seu corpo, abrindo portas para outras formas de viver, mais ricas e coloridas, onde experiências, sensações e sentimentos podem ser compartilhados.

Cada vez mais, Gustavo foi se apropriando do espaço da terapia. Esse espaço continente, onde seu gesto era reconhecido como expressão de sua singularidade, o fortaleceu para responder a este mundo marcado por opressões e retaliações no qual se encontra. Ao compreender a agressividade como um gesto saudável, abriu-se a Gustavo a possibilidade dele se defender de um ambiente muitas vezes hostil e instaurar um lugar de crescimento e existência.

Alguns meses após o término dos atendimentos a estagiária foi visitar Gustavo em sua casa, levando consigo os materiais necessários para montar uma pipa para dar de presente para ele e seus irmãos. Os meninos logo quiseram fazer cada um a sua. $\mathrm{O}$ irmão mais novo estava um pouco 
inquieto e em certo momento bateu em sua mãe e correu em direção aos materiais, amassando alguns papéis. Antes que a mãe fizesse qualquer coisa, Gustavo foi até seu irmão, abraçou-o carinhosamente e ajudou-o a brincar. (BUELAU,
2006).

Como nos ensina Clarice Lispector, "É preciso não esquecer e respeitar a violência que temos. As pequenas violências salvam-nos das grandes".

BUELAU, R. M.; INFORSATO, E. A.; LIMA, E. M. F. A. Dreaming together: creativity and aesthetic experiences on the accompaniment of a child. Rev. Ter. Ocup. Univ. São Paulo, v. 20, n. 3, p. 164-170, set./dez. 2009.

\begin{abstract}
This article presents the case-study of a therapeutic accompaniment of a child in social vulnerability. This child was assisted in the Artistic Compositions and Occupational Therapy Permanent Program, of the Occupational Therapy Program, at USP, from 2004 to 2007. This research aim was to contribute for the production of knowledge in the field of the interface between art and health, focusing on the relevance of the creativity and aesthetic experiences in Occupational Therapy processes. Therefore, our objective was to verify how the opening to a creative living strengthens life and make it possible to present the world in a inviting and not threatening way. The accompaniment revealed to be extremely rich for the child process. Through transiting on the city, contacting with other people and cultural elements and creating a play space in the therapeutic relation, it became possible to face the precariousness of life in a creative and healthful way.
\end{abstract}

KEY WORDS: Occupational therapy. Creativeness. Human activities. Child development. Case Studies.

\title{
REFERÊNCIAS
}

BUELAU, R. M. Estudo de caso. Arquivos do PACTO, Laboratório de Estudos e Pesquisa Arte e Corpo em Terapia Ocupacional. Centro de Docência e Pesquisa em TO da USP. São Paulo, 2004. 22 p.

BUELAU, R. M. Relatórios de estágio. Arquivos do PACTO, Laboratório de Estudos e Pesquisa Arte e Corpo em Terapia Ocupacional. Centro de Docência e Pesquisa em TO da USP. São Paulo, 2004.

BUELAU, R. M. Cadernos de registro. Arquivos do PACTO, Laboratório de Estudos e Pesquisa Arte e Corpo em Terapia Ocupacional. Centro de Docência e Pesquisa em TO da USP. São Paulo, 2006.

CASTRO, E. D. Arte, corpo e terapia ocupacional: aproximações, intersecções e desdobramentos. Rev. Ter. Ocup. Univ. São Paulo. São Paulo, v. 11, n.1. p 7-12, 2000.

CASTRO, E. D. Relação terapeuta-paciente no campo da terapia ocupacional. In: Cavalcanti, A.; Galvão, C. (org.). Terapia ocupacional. Fundamentação e prática. Rio de Janeiro: GuanabaraKoogan, 2007. p. 28-37.

COSTA, J. F. O vestígio e a aura: corpo e consumismo na moral do espetáculo. Ed. Gramond Universitária, 2004. p. 89-127.

DEJOURS, C. Por um novo conceito de saúde. Rev. Bras. Saude Ocup., v. 14, n.54, abr-jun, 1986.

GIL, A. C. Como elaborar projetos de pesquisa. 4a ed. São Paulo: Atlas, 1991. 4 ed.
GIL, A. C. Métodos e técnicas de pesquisa social. 5a ed. São Paulo: Atlas, 1999.

LIMA, E. A. Clínica e criação: um estudo sobre o lugar das atividades nas práticas em saúde mental, 1999. 183f. Dissertação (Mestrado) - PUC. São Paulo, 1999.

MAY, R. A natureza da criatividade. In: A coragem de criar. Rio de Janeiro: Vozes, 1971. p. 35-53.

ROLNIK, S. Subjetividade, ética e cultura nas práticas em Saúde Mental. Programa de Estudos Pós-Graduados em Psicologia Clínica da PUC-SP, 1996. (mimeo).

SAFRA, G. A face estética do self: teoria e clínica. São Paulo: Unimarco Editora, 2005.

SAFRA. G. A po-ética na clínica contemporânea. Aparecida do Norte: Idéias e Letras, 2004.

VILLARES, C. C. Abordagem qualitativa em terapia ocupacional: um panorama geral. Rev. Ter. Ocup. Univ. São Paulo. v. 9, n. 3, 1998.

WINNICOTT, D. W. O brincar e a realidade. Rio de Janeiro: Imago, 1975.

WINNICOTT, D. W. Privação e delinqüência. São Paulo: Martins Fontes, 1994.

WINNICOTT, D. W. Tudo começa em casa. São Paulo: Martins Fontes, 1996. 